\title{
Increased Slug and decreased E-cadherin expression is related to poor prognosis in patients with gastric cancer
}

\author{
Yasuto Uchikado $\cdot$ Hiroshi Okumura $\cdot$ Sumiya Ishigami $\cdot$ Tetsuro Setoyama \\ Masataka Matsumoto $\cdot$ Tetsuhiro Owaki $\cdot$ Yoshiaki Kita $\cdot$ Shoji Natsugoe
}

Received: 19 May 2010/Accepted: 29 August 2010/Published online: 28 January 2011

(C) The International Gastric Cancer Association and The Japanese Gastric Cancer Association 2011

\begin{abstract}
Background The expression of E-cadherin correlates with the progression and metastasis of gastric cancer. Slug, a member of the snail family of transcriptional factors, is a newly identified factor that represses transcription of the E-cadherin gene. The purpose of the present study was to evaluate the clinical significance of E-cadherin and Slug expression in gastric cancer.

Methods Immunohistochemistry was used to investigate the expression of E-cadherin and Slug proteins in 164 patients with gastric cancer. The relationships between the expression of these proteins and clinicopathological factors, including prognosis, were analyzed.

Results Positive expression of E-cadherin and Slug was observed in 43.9 and $29.9 \%$ of cases, respectively. Tumors with reduced E-cadherin or positive Slug expression had greater extent of lymph node metastasis, lymphatic invasion, and venous invasion, and were at a worse stage than the tumors with preserved E-cadherin or negative Slug expression. Slug expression was significantly correlated with reduced E-cadherin expression; 37 of the 49 (75.5\%) tumors with positive Slug expression had reduced E-cadherin expression $(P=0.0008)$. Patients with reduced E-cadherin expression or positive Slug expression had poor clinical outcomes. In the group with preserved E-cadherin expression, the 5-year survival rate was better for patients who were negative for Slug expression than for those who
\end{abstract}

Y. Uchikado ( $₫) \cdot$ H. Okumura · S. Ishigami · T. Setoyama ·

M. Matsumoto · T. Owaki - Y. Kita - S. Natsugoe

Department of Surgical Oncology, Digestive Surgery,

Graduate School of Medicine, Kagoshima University,

Sakuragaoka 8-35-1, Kagoshima 890-8520, Japan

e-mail: just-u@m.kufm.kagoshima-u.ac.jp were positive for Slug expression $(P=0.0001)$. However, multivariate analysis indicated that E-cadherin expression and Slug expression were not independent prognostic factors.

Conclusions Evaluation of not only the expression of E-cadherin, but also the coexpression of E-cadherin and Slug in patients with preserved E-cadherin expression would be useful for predicting malignant properties of gastric cancer.

Keywords Gastric cancer - E-cadherin · Slug · Transcriptional factor $\cdot$ Prognosis

\section{Introduction}

Advanced gastric cancer is one of the most aggressive carcinomas of the gastrointestinal tract because it leads to lymph node metastasis, hematogenous metastasis, and peritoneal dissemination [1]. The malignant potential of gastric cancer has been studied using various biological markers [2]. E-cadherin is a major cell-cell adhesion molecule that plays a critical role in the development and maintenance of cell polarity and tissue architecture [3, 4]. The expression of E-cadherin is regulated at the genetic level via processes such as mutation, loss of heterozygosity, and hypermethylation of its promoter [5-7]. In gastric cancer, loss of E-cadherin expression is associated with tumor dedifferentiation, invasiveness, and metastasis, as well as prognosis $[8,9]$. Slug is a member of the snail family of repressors, and is expressed in the neural crest and mesodermal cells emigrating from the primitive streak in chick embryos [10]. Recently, another critical role of Slug has been reported. Slug binds to E-box elements in the proximal E-cadherin promoter and represses transcription 
of the E-cadherin gene [11, 12]. Some reports have found that Slug plays a role in tumor progression in primary human cancers. Castro Alves et al. [13, 14] reported the mRNA expression of Slug and E-cadherin in gastric cancer. But Slug protein expression has not yet been reported in primary gastric cancer.

The purpose of the present study was to examine the clinical significance of Slug expression and the correlation between Slug expression and E-cadherin expression in primary gastric cancer.

\section{Patients and methods}

Patients and specimens

The study subjects, 164 patients with gastric cancer (113 males and 51 females), underwent gastrectomy with lymph node dissection between 1990 and 1998 at Kagoshima University Hospital, Kagoshima, Japan. The patients ranged in age from 22 to 88 years (mean 65 years). None of these patients underwent endoscopic mucosal resection, palliative resection, or preoperative chemotherapy, or had synchronous or metachronous multiple cancer in other organs. Specimens of cancer tissues and noncancerous tissues were collected from the patients after informed consent had been obtained, in accordance with the institutional guidelines of our hospital.

Clinicopathological findings were based on the criteria of the tumor node metastasis (TNM) classification of the International Union against Cancer [15]. Histopathological types of gastric cancer were classified into two types, intestinal type and diffuse type. The intestinal type was further classified into three differentiated types: well-differentiated (tub1), moderately differentiated (tub2), and papillary differentiated (pap); and the diffuse type was classified into two undifferentiated types: diffuse-adherent (por1) and diffuse-scattered (tub2).

All patients were followed up after discharge, with $\mathrm{X}$-ray examination and tumor marker assays (carcinoembryonic antigen and carbohydrate antigen 19-9) performed every 1-3 months, computed tomography performed every 3-6 months, and ultrasonography performed every 6 months. Endoscopic examinations were performed when necessary. Postoperative follow-up data were obtained from all patients, with a median follow-up period of 35 months (range 1-136 months).

Immunohistochemical staining and evaluation

After the primary lesions were fixed in $10 \%$ formaldehyde, and routinely embedded in paraffin, 3- $\mu$ m-thick sections were prepared for immunohistochemistry. Immunohistochemical staining was performed using the avidin-biotin peroxidase method as described previously [16]. Briefly, after the sections were deparaffinized in xylene and dehydrated in ethanol, endogenous peroxidase activity was blocked by incubating the sections for $15 \mathrm{~min}$ in $0.3 \% \mathrm{H}_{2} \mathrm{O}_{2}$ in methanol. Then the sections were heated in a citrate buffer $(10 \mathrm{mM}, \mathrm{pH} 6.0)$ at $120^{\circ} \mathrm{C}$ for $10 \mathrm{~min}$ in an autoclave to reveal the antigen. After cooling, the sections were preincubated in $3 \%$ skim milk/ phosphate buffered saline (PBS) for $30 \mathrm{~min}$ at room temperature. Next, the sections were incubated with either anti-E-cadherin monoclonal antibody (1:100; E-cadherin:HECD-1, Takara Biotechnology, Japan) or anti-Slug polyclonal antibody (1:100; Slug:D-19; Santa Cruz Biotechnology, Santa Cruz, CA, USA) overnight at $4^{\circ} \mathrm{C}$. The sections were then incubated with biotinylated anti-goat IgG and avidin-biotin peroxidase using the Vectastain Elite ABC kit (Vector Laboratories, Burlingame, CA, USA), and reactions were visualized using diaminobenzidine tetrahydrochloride. The sections were then slightly counterstained with hematoxylin.

Evaluation of immunohistochemistry was independently performed by two investigators (Y.U. and S.N.). Expression of E-cadherin was compared between malignant cells and normal epithelial cells located distant from the tumor. Tumor cells that stained as strongly as normal epithelial cells were considered to have preserved expression, whereas those that exhibited weaker staining patterns than normal epithelial cells, and those that did not stain at all were considered to have reduced expression [17]. For Slug, positive expression was defined as detectable immunoreaction in the perinuclear and other cytoplasmic regions of more than $10 \%$ of the cancer cells. To evaluate the expression of Slug and E-cadherin, 10 fields (within the tumor and at the invasive front) were selected, and expression in 1000 tumor cells (100 cells/field) was evaluated using high-power $(\times 200)$ microscopy.

\section{Statistical analysis}

Statistical analysis of group differences was performed using the $\chi^{2}$ test and $t$ test. The Kaplan-Meier method was used for survival analysis, and differences in survival were estimated using the log-rank test. Prognostic factors were examined by univariate and multivariate analyses (Cox proportional hazards regression model). A value of $P<0.05$ was considered statistically significant. All statistical analyses were performed using the JMP 5 for Windows software (SAS Institute, Cary, NC, USA). 


\section{Results}

Expression of E-cadherin and Slug in gastric cancer and normal gastric mucosa

E-cadherin expression was observed on the cell membrane of cancer cells, indicating preserved expression, in $43.9 \%$ of all patients (72 of 164; Fig. 1a, b). Expression of Slug was observed in the cytoplasm of cancer cells in $29.9 \%$ of all patients (49 of 164; Fig. 1c, d). The expression of E-cadherin and Slug in normal gastric mucosa is shown in Fig. 1i, j. In normal cells E-cadherin expression was shown in the cell membrane; no expression of Slug was shown in the cytoplasm.

\section{E-cadherin and Slug expression in relation to clinicopathological findings}

E-cadherin expression was significantly associated with the following clinicopathological parameters: lymph node metastasis, stage, lymphatic invasion, and venous invasion (Table 1). The tumors with reduced E-cadherin expression had greater extent of lymph node metastasis, lymphatic invasion, and venous invasion than the tumors with
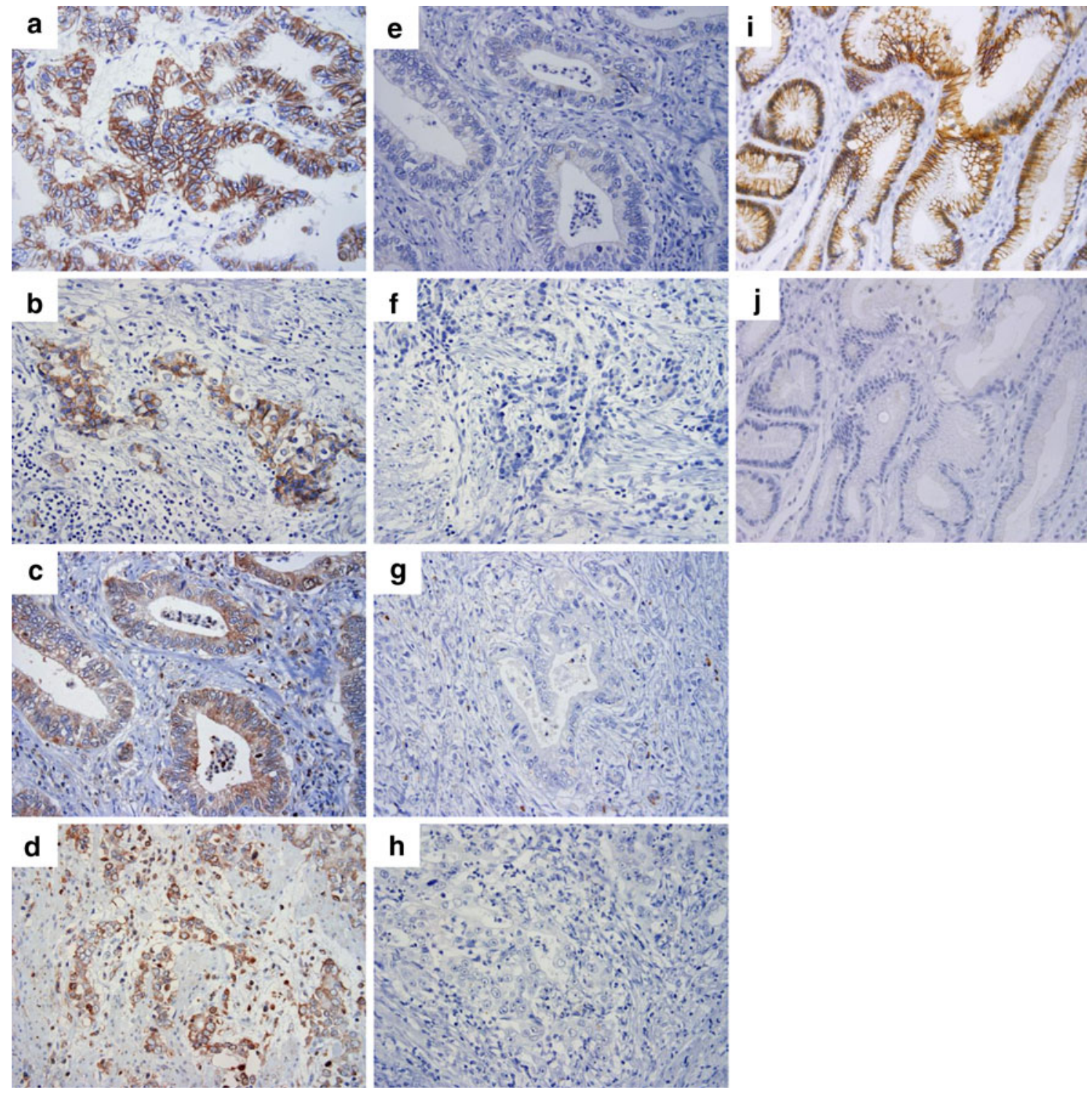

Fig. 1 Expression of E-cadherin and Slug in gastric cancer (GC) and normal gastric mucosa. E-cadherin expression in GC showed two histopathological types; intestinal type (a, e) and diffuse type (b, f). a, b Preserved expression of E-cadherin is detected in the cell membrane; $\mathbf{e}, \mathbf{f}$ reduced expression of E-cadherin. Slug expression in GC showed two histopathological types; intestinal type $(\mathbf{c}, \mathbf{g})$ and diffuse type $(\mathbf{d}, \mathbf{h})$. c, d expression of Slug is detected in the cytoplasm; $\mathbf{g}$, $\mathbf{h}$ no expression of Slug; $\mathbf{i}$ E-cadherin expression in the cell membrane of normal cells; $\mathbf{j}$ no expression of Slug in normal cells. a-j $\times 400$ 
Table 1 E-cadherin and Slug expression in relation to clinicopathological findings

\begin{tabular}{|c|c|c|c|c|c|c|c|}
\hline Characteristics & Total $(n=164)$ & $\begin{array}{l}\text { E-cadherin } \\
\text { Preserved }(n=72)\end{array}$ & $\begin{array}{l}\text { E-cadherin } \\
\text { Reduced }(n=92)\end{array}$ & $P$ & $\begin{array}{l}\text { Slug } \\
\text { Positive }(n=49)\end{array}$ & $\begin{array}{l}\text { Slug } \\
\text { Negative }(n=115)\end{array}$ & $P$ \\
\hline Age (years) & & $66 \pm 12$ & $64 \pm 13$ & NS & $65 \pm 12$ & $64 \pm 13$ & NS \\
\hline \multicolumn{8}{|l|}{ Sex } \\
\hline Male & 113 & 53 & 60 & \multirow[t]{2}{*}{ NS } & 27 & 86 & \multirow[t]{2}{*}{0.014} \\
\hline Female & 51 & 19 & 32 & & 22 & 29 & \\
\hline \multicolumn{8}{|c|}{ Histopathological type } \\
\hline \multicolumn{8}{|l|}{ Intestinal type } \\
\hline pap & 5 & 3 & 2 & \multirow[t]{3}{*}{ NS } & 2 & 3 & \multirow[t]{3}{*}{ NS } \\
\hline tub1 & 38 & 18 & 20 & & 14 & 24 & \\
\hline tub2 & 45 & 26 & 19 & & 11 & 34 & \\
\hline \multicolumn{8}{|l|}{ Diffuse type } \\
\hline por1 & 24 & 8 & 16 & \multirow[t]{2}{*}{ NS } & 10 & 14 & \multirow[t]{2}{*}{ NS } \\
\hline por2 & 52 & 17 & 35 & & 12 & 40 & \\
\hline \multicolumn{8}{|c|}{ Tumor depth (pT) } \\
\hline pT1 & 72 & 39 & 33 & \multirow[t]{4}{*}{ NS } & 14 & 58 & \multirow[t]{4}{*}{0.036} \\
\hline pT2 & 53 & 18 & 35 & & 18 & 35 & \\
\hline pT3 & 34 & 13 & 21 & & 14 & 20 & \\
\hline pT4 & 5 & 2 & 3 & & 3 & 2 & \\
\hline \multicolumn{8}{|c|}{ Lymph node metastasis $(\mathrm{pN})$} \\
\hline pNO & 93 & 50 & 43 & \multirow[t]{4}{*}{0.015} & 18 & 75 & \multirow[t]{4}{*}{0.0083} \\
\hline $\mathrm{pN} 1$ & 40 & 13 & 27 & & 18 & 22 & \\
\hline $\mathrm{pN} 2$ & 16 & 3 & 13 & & 6 & 10 & \\
\hline $\mathrm{pN} 3$ & 15 & 6 & 9 & & 7 & 8 & \\
\hline \multicolumn{8}{|c|}{ Distant metastasis (pM) } \\
\hline pM0 & 153 & 66 & 87 & \multirow[t]{2}{*}{ NS } & 43 & 110 & \multirow[t]{2}{*}{ NS } \\
\hline pM1 & 11 & 6 & 5 & & 6 & 5 & \\
\hline \multicolumn{8}{|l|}{ pStage } \\
\hline I & 94 & 48 & 46 & \multirow[t]{4}{*}{0.016} & 20 & 74 & \multirow[t]{4}{*}{0.049} \\
\hline II & 24 & 11 & 13 & & 10 & 14 & \\
\hline III & 23 & 5 & 18 & & 7 & 16 & \\
\hline IV & 23 & 8 & 15 & & 12 & 11 & \\
\hline Lymphatic inv & asion & & & & & & \\
\hline Negative & 70 & 39 & 31 & 0.0084 & 12 & 58 & 0.0017 \\
\hline Positive & 94 & 33 & 61 & & 37 & 57 & \\
\hline Venous invasi & & & & & & & \\
\hline Negative & 115 & 57 & 58 & 0.024 & 28 & 87 & 0.02 \\
\hline Positive & 49 & 15 & 34 & & 21 & 28 & \\
\hline Hematogenous & recurrence & & & & & & \\
\hline Negative & 144 & 63 & 81 & NS & 41 & 103 & NS \\
\hline Positive & 20 & 9 & 11 & & 8 & 12 & \\
\hline Peritoneal recu & rrence & & & & & & \\
\hline Negative & 145 & 67 & 78 & NS & 38 & 107 & 0.0067 \\
\hline Positive & 19 & 5 & 14 & & 11 & 8 & \\
\hline Slug expressio & & & & & & & \\
\hline Positive & 49 & 12 & 37 & 0.008 & & & \\
\hline Negative & 115 & 60 & 55 & & & & \\
\hline
\end{tabular}

NS not significant 
preserved expression $(P=0.015,0.0084$, and 0.024 , respectively), and these tumors were at a worse stage than those with preserved E-cadherin expression $(P=0.016)$.

Slug expression was associated with gender, depth of tumor invasion, lymph node metastasis, stage, lymphatic invasion, venous invasion, and peritoneal recurrence (Table 1). Tumors that were positive for Slug expression were more frequently observed in female patients than in male patients $(P=0.014)$. The tumors that were positive for Slug expression invaded deeper, had more lymph node metastasis, lymphatic invasion, and venous invasion, and recurred more in the peritoneal cavity than those that were negative for Slug expression $(P=0.036,0.0083,0.0017$, and 0.02, 0.0067, and, respectively), and these tumors were at a worse stage than those that were negative for Slug expression $(P=0.049)$.

In regard to histopathological type, the expression of E-cadherin or Slug was not associated with any subtype (Table 1).
The presence of Slug expression was significantly correlated with reduced E-cadherin expression (Table 1). Thirty-seven of the $49(75.5 \%)$ tumors that were positive for Slug expression had reduced E-cadherin expression $(P=0.0008)$.

Relationship between Slug expression and clinicopathological findings according to E-cadherin expression

The tumors were divided into the E-cadherin preserved group and E-cadherin reduced group. In the E-cadherin preserved group, the expression of Slug was related to lymph node metastasis, distant metastasis, stage, venous invasion, hematogenous recurrence, and peritoneal recurrence, while in the E-cadherin reduced group the expression of Slug was related to lymphatic invasion (Table 2).

Table 2 Relationship between Slug expression and clinicopathological findings according to E-cadherin expression

\begin{tabular}{|c|c|c|c|c|c|c|}
\hline & \multicolumn{2}{|c|}{ E-cadherin preserved } & \multirow[t]{2}{*}{$P$} & \multicolumn{2}{|c|}{ E-cadherin reduced } & \multirow[t]{2}{*}{$P$} \\
\hline & $\begin{array}{l}\text { Slug positive } \\
(n=12)\end{array}$ & $\begin{array}{l}\text { Slug negative } \\
(n=60)\end{array}$ & & $\begin{array}{l}\text { Slug positive } \\
(n=37)\end{array}$ & $\begin{array}{l}\text { Slug negative } \\
(n=55)\end{array}$ & \\
\hline \multicolumn{7}{|c|}{ Histopathological type } \\
\hline Intestinal type & 9 & 38 & NS & 18 & 23 & NS \\
\hline Diffuse type & 3 & 22 & & 19 & 32 & \\
\hline \multicolumn{7}{|c|}{ Tumor depth (pT) } \\
\hline pT1 and pT2 & 7 & 50 & NS & 25 & 43 & NS \\
\hline pT3 and pT4 & 5 & 10 & & 12 & 12 & \\
\hline \multicolumn{7}{|c|}{ Lymph node metastasis (pN) } \\
\hline Negative & 4 & 46 & 0.0043 & 14 & 29 & NS \\
\hline Positive & 8 & 14 & & 23 & 26 & \\
\hline \multicolumn{7}{|c|}{ Distant metastasis (pM) } \\
\hline pM0 & 8 & 58 & 0.0036 & 35 & 52 & NS \\
\hline pM1 & 4 & 2 & & 2 & 3 & \\
\hline \multicolumn{7}{|l|}{ pStage } \\
\hline I and II & 7 & 52 & 0.032 & 23 & 36 & NS \\
\hline III and IV & 5 & 8 & & 14 & 19 & \\
\hline \multicolumn{7}{|c|}{ Lymphatic invasion } \\
\hline Negative & 4 & 35 & NS & 8 & 23 & 0.041 \\
\hline Positive & 8 & 25 & & 29 & 32 & \\
\hline \multicolumn{7}{|l|}{ Venous invasion } \\
\hline Negative & 6 & 51 & 0.012 & 22 & 36 & NS \\
\hline Positive & 6 & 9 & & 15 & 19 & \\
\hline \multicolumn{7}{|c|}{ Hematogenous recurrence } \\
\hline Negative & 7 & 56 & 0.0034 & 34 & 47 & NS \\
\hline Positive & 5 & 4 & & 3 & 8 & \\
\hline \multicolumn{7}{|c|}{ Peritoneal recurrence } \\
\hline Negative & 9 & 58 & 0.0215 & 29 & 49 & NS \\
\hline Positive & 3 & 2 & & 8 & 6 & \\
\hline
\end{tabular}


Relationships between prognosis and expression of E-cadherin or Slug

No patient died of postoperative complications within 30 days of the beginning of the study period. The 5-year survival rate of patients with tumors with preserved E-cadherin expression was $88.6 \%$, whereas the rate for patients with reduced E-cadherin expression was $63.5 \%$. Thus, there was a significant difference in 5-year survival between the groups with preserved and reduced expression of E-cadherin ( $P=0.022$; Fig. 2a). The 5-year survival rate of patients who were negative and positive for the expression of Slug was 78.0 and $54.3 \%$, respectively, and this difference was also significant $(P=0.015$; Fig. $2 b)$.

In stage II and III patients, data showed no difference in survival between the patients with Slug expression and those without Slug expression.

Relationships between prognosis and Slug expression according to E-cadherin expression

In the E-cadherin preserved group, the 5-year survival rate of patients who were negative and positive for Slug
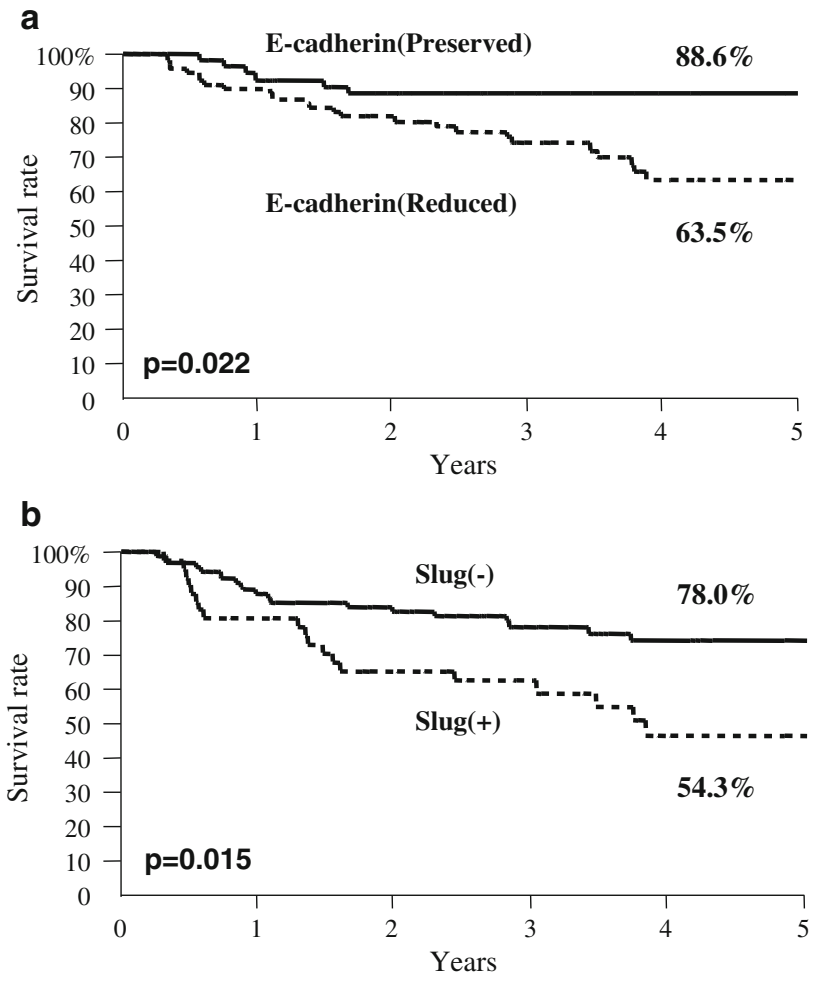

Fig. 2 Postoperative 5-year survival curves of patients according to the expression of E-cadherin (a) or Slug (b). a There was a significant difference in survival between the patients with preserved and those with reduced expression of E-cadherin $(P=0.022)$. $\mathbf{b}$ There was also a significant difference in 5 -year survival between the patients with $(+)$ and without $(-)$ the expression of Slug $(P=0.015)$ expression was 92.0 and $46.7 \%$, respectively, and this difference was significant $(P=0.0001$; Fig. 3a). However, in the E-cadherin reduced group, there was no significant difference between patients positive and negative for Slug expression (Fig. 3b).

Univariate and multivariate analyses of prognostic factors

Table 3 shows the univariate and multivariate analyses of factors related to patient prognosis. The univariate analysis showed that the following factors were significantly related to postoperative survival: depth of tumor invasion, lymph node metastasis, stage, lymphatic invasion, venous invasion, E-cadherin expression, Slug expression, and combination of E-cadherin and Slug expression $(P<0.05)$. Multivariate regression analysis indicated that depth of invasion and lymph node metastasis were independent prognostic factors, but indicated that E-cadherin expression, Slug expression, and the combination of E-cadherin

a

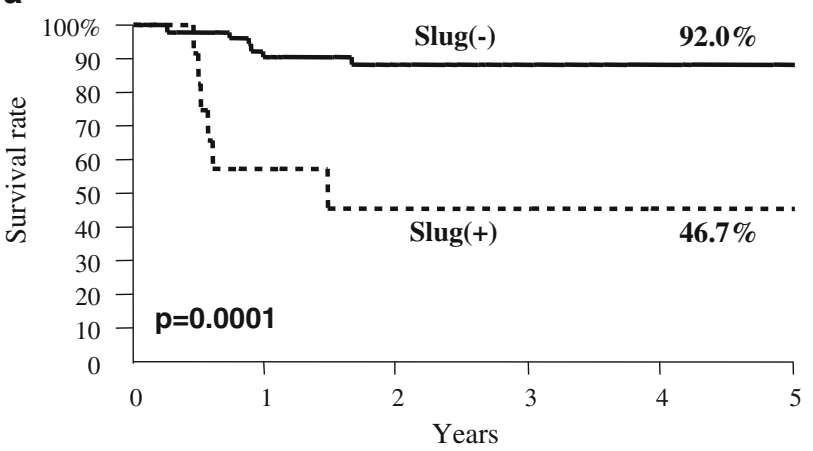

b

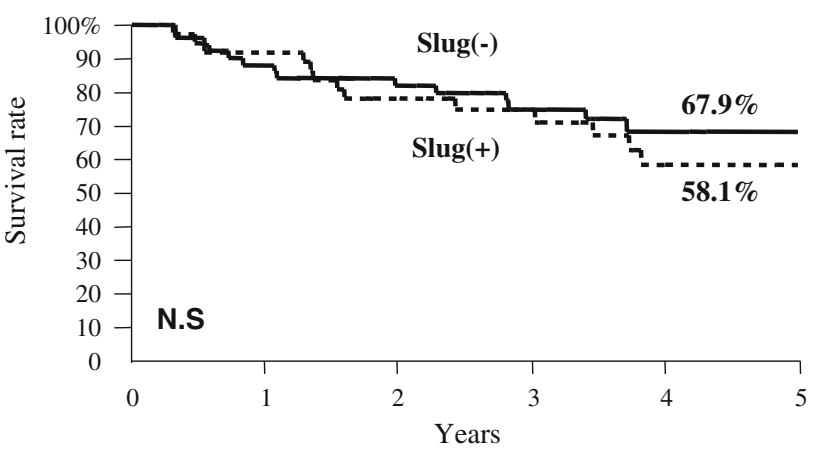

Fig. 3 Postoperative 5-year survival curves in the patients with (+) and without $(-)$ Slug expression according to E-cadherin expression. a In the group with preserved E-cadherin expression, the patients without Slug expression (-) had a better outcome than those with Slug expression $(+)(P=0.0001)$. b In the group with reduced E-cadherin expression, there was no difference in outcome between the patients with Slug expression $(+)$ and those without Slug expression (-). NS not significant 
Table 3 Univariate and multivariate analyses of prognostic factors in gastric cancer

\begin{tabular}{|c|c|c|c|c|}
\hline Independent factors & Univariate $P$ & Multivariate $P$ & Hazard ratio & $95 \%$ Confidence interval \\
\hline \multicolumn{5}{|l|}{ Tumor depth (pT) } \\
\hline pT1 and pT2/pT3 and pT4 & $<0.0001$ & 0.0019 & 2.95 & $1.48-6.11$ \\
\hline \multicolumn{5}{|l|}{ Lymph node metastasis $(\mathrm{pN})$} \\
\hline Negative/positive & $<0.0001$ & $<0.0001$ & 7.41 & $2.68-26.24$ \\
\hline \multicolumn{5}{|l|}{ Venous invasion } \\
\hline Negative/positive & $<0.0001$ & 0.082 & 1.87 & $0.93-3.96$ \\
\hline \multicolumn{5}{|c|}{ Combination of E-cadherin and Slug expression } \\
\hline E-cadherin $(+)$ Slug $(-)$ /others & 0.006 & 0.721 & 3.01 & $0.66-13.62$ \\
\hline
\end{tabular}

and Slug expression were not independent prognostic factors.

\section{Discussion}

Previous studies have indicated that reduction of E-cadherin expression ranges from 51 to $72 \%$ of baseline in gastric cancer specimens, and reduced expression of E-cadherin is associated with histological differentiation, lymph node metastasis, peritoneal dissemination, and poor prognosis $[9,18-20]$. In the present study, $56.1 \%$ of patients with gastric cancer showed reduced expression of E-cadherin, which was associated with lymph node metastasis, stage, lymphatic invasion, venous invasion, and poor prognosis. The present results are almost consistent with previous reports, although reduced E-cadherin expression was not correlated with peritoneal recurrence in the present study.

In the present study and previous studies, although some patients with preserved E-cadherin expression had lymph node metastases and died of recurrence after surgery, most patients survived for a relatively long period without lymph node metastases or recurrence [9, 20]. To investigate the involvement of molecular factors in the regulation of the function of E-cadherin in gastric cancer, we had an interest in Slug, which is a factor that represses transcription of the $E$-cadherin gene [11, 12]. In the present study, we found that positive Slug expression was associated with reduced E-cadherin expression, tumor invasion, lymph node metastasis, stage, lymphatic invasion, venous invasion, peritoneal recurrence, and worse clinical outcomes. In the E-cadherin preserved group, positive Slug expression in these patients was associated with lymph node metastasis, distant metastasis, stage, venous invasion, hematogenous recurrence, peritoneal recurrence, and worse prognosis. Our results, taken together with previous findings that both hematogenous recurrence and peritoneal recurrence are important factors in causing a worse outcome in gastric cancer, suggest that Slug plays an important role not only in the suppression of E-cadherin function, but also in the promotion of tumor invasiveness in patients with preserved E-cadherin expression.

In regard to histopathological type, the expression of E-cadherin or Slug was not associated with any subtype. In colorectal cancer there was no relationship between histopathological type and E-cadherin or Slug expression [21]. The reason for this lack of relationship may be the problem of heterogeneity of E-cadherin or Slug expression in the same section of gastric cancer cells. In early gastric cancer, it was reported that the expression of the mucin phenotype was dependent on genetic change, and was related to tumor aggressiveness [22-24]. It has also been reported that E-cadherin expression was regulated by genetic alterations $[5,6]$. We will need to investigate in future whether there is a correlation between the mucin phenotype and E-cadherin or Slug expression.

Castro Alves et al. [14] reported an analysis of the epithelial-mesenchymal transition demonstrating that Slug upregulation accompanied by E-cadherin downregulation was correlated with the presence of distant metastases and with advanced pTNM stages. There are some important differences between our study and that of Castro Alves et al. [14], as follows: first, all of the patients in our study group underwent curative surgical treatment and their pM1 category consisted of only distant lymph node metastasis, without organ metastasis. Second, our study group included many pN0 patients $(57 \%)$ whose stages were earlier compared to those in the study group of Castro Alves (pN0: $22 \%$ ). Third, the sample sizes were different, 164 in our study versus 59 in the Castro Alves study. Fourth, we performed immunohistochemical analysis that detected only the membranous expression of E-cadherin or the cytoplasmic expression of Slug, whereas they performed reverse transcription- polymerase chain reaction (RT-PCR) analysis that detected all expression signals in the tissues. Although the conclusions of our study and those of Castro Alves were different, it is likely that the downregulation of E-cadherin was a major cause of the poor prognosis of 
gastric cancer patients in our study, with the upregulation of Slug being a component that partly inhibited E-cadherin function.

Slug has an anti-apoptotic effect on leukemia cells [25, 26] and downregulates epithelial markers including desmoplakin and cytokeratin-18 [27, 28]. Additionally, Slug mediates radioresistance and chemoresistance in ovarian cancer cells [29]. These previous findings imply that the anti-apoptotic function, and downregulation of certain adhesion molecules, or treatment resistance can worsen the outcome of patients with preserved E-cadherin expression. In contrast, in the patients with reduced E-cadherin expression in our study, Slug expression did not have a marked effect on prognosis. When E-cadherin expression is reduced in gastric cancer, E-cadherin expression may be regulated not only by Slug but also by other suppressive transcriptional factors such as Snail, SIP-1, or Twist, and by genetic or epigenetic alterations such as DNA mutation or CpG methylation $[5,6,30]$.

Although preserved E-cadherin expression without Slug expression was one prognostic factor in the univariate analysis in the present study, it was not an independent prognostic factor in the multivariate analysis. But Slug expression was significantly and strongly correlated with lymph node metastasis, lymphatic invasion, and peritoneal recurrence. Patients who are positive for Slug expression will require more careful observation. We note that these correlations with Slug expression are novel findings. Especially, positive Slug expression may play a particularly important role in tumors with preserved E-cadherin expression in gastric cancer. Similar results in regard to prognosis were observed in our previous report about the expression of E-cadherin and Slug in esophageal cancer [31], although there were some differences in clinicopathological factors between gastric and esophageal cancer. The expression of Slug in patients with preserved E-cadherin expression was strongly associated with tumor depth and venous invasion in esophageal cancer and with lymph node metastasis and lymphatic invasion in gastric cancer. These data suggest that E-cadherin and Slug might have various different functions according to cell type or cell differentiation.

In conclusion, the expression of E-cadherin and that of Slug were associated with tumor properties, including lymph node metastasis, stage, lymphatic invasion, and venous invasion, as well as with prognosis. Although E-cadherin expression and Slug expression were not independent prognostic factors, the evaluation of both the expression of E-cadherin and the coexpression of E-cadherin and Slug in patients with preserved E-cadherin expression would be useful in predicting malignant properties of gastric cancer.
Acknowledgments This study was supported in part by a Grant-inAid for Scientific Research from the Ministry of Education, Science, Sports and Culture of Japan (No. 17390373).

\section{References}

1. Boyle P. Global burden of cancer. Lancet. 1997;349:23-6.

2. Kyrlagkitsis I, Karamanolis DG. Genes and gastric cancer. Hepatogastroenterology. 2004;51:320-7.

3. Frixen UH, Behrens J, Sachs M, Eberle G, Voss B, Warda A, et al. E-cadherin-mediated cell-cell adhesion prevents invasiveness of human carcinoma cells. J Cell Biol. 1991;113:173-85.

4. Hirohashi S. Inactivation of the E-cadherin-mediated cell adhesion system in human cancers. Am J Pathol. 1998;153:333-9.

5. Tamura G, Yin J, Wang S, Fleisher AS, Zou T, Abraham JM, et al. E-cadherin gene promoter hypermethylation in primary human gastric carcinomas. J Natl Cancer Inst. 2000;92:569-73.

6. Berx G, Becker KF, Hofler H, van Roy F. Mutations of the human E-cadherin (CDH1) gene. Hum Mutat. 1998;12:226-37.

7. Wang HD, Ren J, Zhang L. CDH1 germline mutation in hereditary gastric carcinoma. World J Gastroenterol. 2004;10:3088-93.

8. Shino Y, Watanabe A, Yamada Y, Tanase M, Yamada T, Matsuda M, et al. Clinicopathologic evaluation of immunohistochemical E-cadherin expression in human gastric carcinomas. Cancer. 1995;76:2193-201.

9. Gabbert HE, Mueller W, Schneiders A, Meier S, Moll R, Birchmeier W, et al. Prognostic value of E-cadherin expression in 413 gastric carcinomas. Int J Cancer. 1996;69:184-9.

10. Nieto MA, Sargent MG, Wilkinson DG, Cooke J. Control of cell behavior during vertebrate development by Slug, a zinc finger gene. Science. 1994;264:835-9.

11. Hajra KM, Chen DY, Fearon ER. The SLUG zinc-finger protein represses E-cadherin in breast cancer. Cancer Res. 2002;62:1613-8.

12. Bolos V, Peinado H, Perez-Moreno MA, Fraga MF, Esteller M, Cano A. The transcription factor Slug represses E-cadherin expression and induces epithelial to mesenchymal transitions: a comparison with Snail and E47 repressors. J Cell Sci. 2003;116:499-511.

13. Castro Alves C, Carneiro F, Hoefler H, Becker KF. Role of the epithelial-mesenchymal transition regulator Slug in primary human cancers. Front Biosci. 2009;14:3035-50.

14. Castro Alves C, Rosivatz E, Schott C, Hollweck R, Becker I, Sarbia M, et al. Slug is overexpressed in gastric carcinomas and may act synergistically with SIP1 and Snail in the down-regulation of E-cadherin. J Pathol. 2007;211:507-15.

15. Sobin LH, Wittekind C. TNM classification of malignant tumours. 6th ed. New York: Wiley, International Union Against Cancer; 2002.

16. Hsu SM, Raine L, Fanger H. Use of avidin-biotin-peroxidase complex $(\mathrm{ABC})$ in immunoperoxidase techniques: a comparison between $\mathrm{ABC}$ and unlabeled antibody (PAP) procedures. J Histochem Cytochem. 1981;29:577-80.

17. Shiozaki H, Tahara H, Oka H, Miyata M, Kobayashi K, Tamura $\mathrm{S}$, et al. Expression of immunoreactive E-cadherin adhesion molecules in human cancers. Am J Pathol. 1991;139:17-23.

18. Yonemura Y, Nojima N, Kaji M, Fujimura T, Itoh H, Ninomiya I, et al. E-cadherin and urokinase-type plasminogen activator tissue status in gastric carcinoma. Cancer. 1995;76:941-53.

19. Shun CT, Wu MS, Lin JT, Wang HP, Houng RL, Lee WJ, et al. An immunohistochemical study of E-cadherin expression with correlations to clinicopathological features in gastric cancer. Hepatogastroenterology. 1998;45:944-9. 
20. Yonemura Y, Endou Y, Kimura K, Fushida S, Bandou E, Taniguchi K, et al. Inverse expression of S100A4 and E-cadherin is associated with metastatic potential in gastric cancer. Clin Cancer Res. 2000;6:4234-42.

21. Shioiri M, Shida T, Koda K, Oda K, Seike K, Nishimura M, et al. Slug expression is an independent prognostic parameter for poor survival in colorectal carcinoma patients. $\mathrm{Br} \mathrm{J}$ Cancer. 2006;94:1816-22.

22. Morohara K, Tajima Y, Nakao K, Nishino N, Aoki S, Kato M, et al. Gastric and intestinal phenotypic cell marker expressions in gastric differentiated-type carcinomas: association with E-cadherin expression and chromosomal changes. J Cancer Res Clin Oncol. 2006;132:363-75.

23. Saito A, Shimoda T, Nakanishi Y, Ochiai A, Toda G. Histologic heterogeneity and mucin phenotypic expression in early gastric cancer. Pathol Int. 2001;51:165-71.

24. Tajima Y, Yamazaki K, Makino R, Nishino N, Aoki S, Kato M, et al. Gastric and intestinal phenotypic marker expression in early differentiated-type tumors of the stomach: clinicopathologic significance and genetic background. Clin Cancer Res. 2006;12:6469-79.

25. Hemavathy K, Ashraf SI, Ip YT. Snail/slug family of repressors: slowly going into the fast lane of development and cancer. Gene. 2000;257:1-12.
26. Inukai $\mathrm{T}$, Inoue A, Kurosawa $\mathrm{H}$, Goi K, Shinjyo $\mathrm{T}$, Ozawa $\mathrm{K}$, et al. SLUG, a ces-1-related zinc finger transcription factor gene with antiapoptotic activity, is a downstream target of the E2A-HLF oncoprotein. Mol Cell. 1999;4:343-52.

27. Cano A, Perez-Moreno MA, Rodrigo I, Locascio A, Blanco MJ, del Barrio MG, et al. The transcription factor snail controls epithelial-mesenchymal transitions by repressing E-cadherin expression. Nat Cell Biol. 2000;2:76-83.

28. Nieto MA. The snail superfamily of zinc-finger transcription factors. Nat Rev Mol Cell Biol. 2002;3:155-66.

29. Kurrey NK, Jalgaonkar SP, Joglekar AV, Ghanate AD, Chaskar PD, Doiphode RY, et al. Snail and slug mediate radioresistance and chemoresistance by antagonizing p53-mediated apoptosis and acquiring a stem-like phenotype in ovarian cancer cells. Stem Cells. 2009;27:2059-68.

30. Rosivatz E, Becker I, Specht K, Fricke E, Luber B, Busch R, et al. Differential expression of the epithelial-mesenchymal transition regulators snail, SIP1, and twist in gastric cancer. Am J Pathol. 2002;161:1881-91.

31. Uchikado Y, Natsugoe S, Okumura H, Setoyama T, Matsumoto $\mathrm{M}$, Ishigami S, et al. Slug expression in the E-cadherin preserved tumors is related to prognosis in patients with esophageal squamous cell carcinoma. Clin Cancer Res. 2005;11:1174-80. 